\title{
Knowledge Management as a Tool for Improving Business Processes: An Action Research Approach
}

\author{
Aurora Martínez-Martínez (D), Luis Manuel Cerdá Suárez (D), Roberto Sánchez Montero iD, Eva Asensio del Arco iD \\ Universidad Politécnica de Cartagena/Universidad Internacional de la Rioja (Spain) \\ aurora.martinez@upct.es, luis.cerda@unir.net,robertosanchezmontero@hotmail.com,eva.asensio@unir.net
}

Received: November 2017

Accepted: January 2018

\begin{abstract}
:
Purpose: The aim of this study is to investigate the importance of Knowledge Management as a tool for improving business processes in a different context from the industrial organizations, as an archaeological museum.

Design/methodology/approach: Using data collected from the National Museum of the Sultanate of Oman in Muscat, a CMP methodology (business process improvement cycle) for analysis and improvement of processes business is designed and validated. This application is described as an eight phases process based on Six Sigma DMAIC.
\end{abstract}

Findings: As the results obtained by the process improvement initiative show, we highlight the relevance of the improvement in all aspects regarding the security in showcases in that context.

Research limitations/implications: The complexity of implementing indicators and the partial vision of the project as data were only obtained from a part of one of the companies involved in the construction of the museum. An important implication of this paper is in order to present a methodology to improve the museum processes focusing on the reduction of errors and also adding value for the visitors.

Practical implications: The relevance to intervene on certain relevant variables at different levels of management performance is verified.

Social implications: Improving the quality of leisure services in order to the identification of certain challenges regarding the nature and competitiveness of cultural services.

Originality/value: The current work has served as a repository of knowledge applicable to new similar projects, in which to take into account the peculiarities of each case and in particular the level of quality demanded by the client in a cultural context. It is important to take into account the degree of avoidable dissatisfaction (number of solvable problems that would lead to dissatisfaction), the opportunity for improvement, the reduction of operational waste and the need for coordination.

Keywords: knowledge management, business processes, improvement, security, museum

\section{Introduction}

Nowadays, museums are a relevant part of the cultural system and leisure of all countries (Kiourt, Koutsoudis \& Pavlidis, 2016; Nonaka \& Takeuchi, 1995). According to Pallud and Straud (2014), The Louvre Museum in Paris, for example, reported 6.1 million visitors in 2000 and 8.8 million visitors in 2011 . For this reason, in the last decades 
museums are among the most socially valued cultural institutions in the world and their social importance has been growing since the end of the 1980s (Ahmad, Abbas, Yusof \& Taib, 2013).

This increased interest in museums can be explained by the diverse social and economic advantages that they can offer, such as providing new community/social space, improving quality of life for residents and providing learning resources and support. In this line, a study commissioned by the European Union indicates that culture is also closely related to innovation and creativity (KEA European Affairs, 2009).

Specifically related to business process in a cultural context, museums are worth investigating in Information Systems research because they represent a relevant environment in comparison to the business context on which past IS research has mainly focused (Camarero, Garrido \& Vicente, 2015).

Based on literature and practices regarding of process improvement methodologies in cultural organizations, this research describes the application in a recent real project. The evolution of business processes in organizations toward an experience event or phenomenon requires an analysis of the role of technologies and information systems in experiential and leisure contexts (De Graaf, Dessouky \& Müller, 2014).

In marketing studies, design of stores and establishments has been principally studied via criteria for commercial purposes. However, in this research we have decided to focus on an experiential environment and we considered several conditions that reflect the dimensions of experience in a modern museum in Oman. For this reason, we present in this paper an initial exploration into how the design and the business processes affect visit and experience inside the museum.

As relevant cultural icons and representations, museums are an appropriate setting to study how to serve to the public, both natives and tourists (Gómez-Martín, 2015). In this context, esthetics appears as one of the most important design criteria for museum experiences. Since an increasing number of museums worldwide are facilitating or reinforcing intentions to visit the physical sites, we can argue that visitors represent potential clients to be attracted to museums. Obviously, our research findings can be generalized to this context as well.

According to several authors (Entradas-Silva, Henriques, Henriques \& Coelho, 2016; De Backer, Peeters, Buffel, Kindekens, Romero-Reina, Elias et al., 2014), we can hypothesize that well-designed museum will attract visitors and that an attractive environment may influence visitors to return to it or even induce visitors to regularly visit a physical museum as a future leisure activity. Although well designed museums should influence behavior and inspire visits to these institutions, extant research has not documented this phenomenon at any level of application.

This work aims to expose the improvement of the security installation process in showcases for the National Museum of Oman (NMO) in its capital, Muscat. Accordingly, in the current research we identify variables that play a role and influence in a specific experiential environment, namely, a relevant high culture museum location. The client does not coordinate the execution of various processes (in fact there is no Security Manager). The absence of a procedure known and agreed upon by all gives rise to important delays in the work related to security in the installation of display showcases. In a National Museum, satisfaction is intimately related to management, service and quality.

In essence, the aim of this paper is based on the application of methodologies of processes to project and eliminate diverse white spaces. The "white space" is the gap between business process steps. It exists where a deliverable is passed between two departments, where a message needs to be transferred to somebody else, where control is passed. It is a question of solving or at least alleviating the effect of the following problems and areas of improvement: lack of awareness of the process and of the need for coordination, work in a "siloitis" environment (each company dealt with its plot under its own criteria and objectives).

Furthermore and as a consequence, in this paper the objectives are the following:

- To improve process speed by eliminating activities that do not add value.

- To innovate to improving working methods by installing correctly on its first at-tempt.

- To increase agility, being able to react to rejections, analyze, repair and deliver to inspection again. 
According to these objectives and in terms of the application of the CMP (business process improvement cycle) methodology here presented, it is very important to emphasize the following specific actions in the museum as a unit of analysis:

- Learn to do it right the first time.

- Alignment with client.

- Being able to react to rejections, analyze, repair and turn in inspection again (in relation to the assembly of alarms in showcases and inspection).

- Gain confidence to propose changes and improvements.

- Alignment with other processes.

- Study relationships with other processes to align with them toward the common goal.

- Do not block the work of the other processes (mainly the end of the Objects Installation process).

Particularly, we present the improvement of the Process of Security Installation in showcases. To achieve this improvement, we worked on developing organizational coordination, studying the business processes and their connections.

The project on which the case study is carried out was awarded by the Ministry of Heritage and Culture to five companies as showed in Figure 1. The figure subcontract work shows the official contracts, to which the project is awarded but in turn each of them has been able to subcontract to other organisations. Each of these companies subcontracted work to third parties, which in turn had their own employees. It is important to notice it because it can be produced more "white spaces" when more organisations participate in the business processes. Furthermore, each company comes from a different country with personnel from varied cultures.

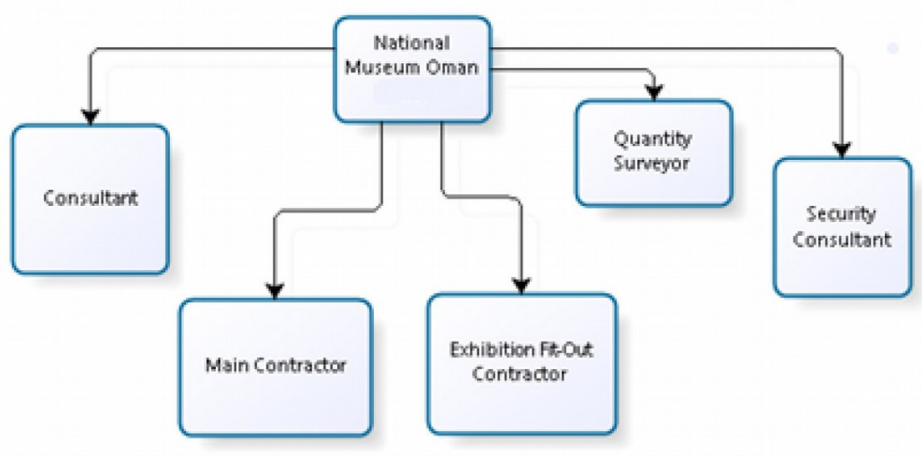

Figure 1. General map of the work contractors

It is a newly built museum, with an area of $4000 \mathrm{~m}^{2}$, located in an emblematic area in the capital city. It has 247 showcases of 22 models (with varied characteristics, manufacturing materials and sizes), about 7,000 collection objects (artifacts) and an interactive system where the Omani history is recreated. It is the first museum of these characteristics in the Middle East.

The work was divided into two main areas: Construction of the new building (which was commissioned by the Main Contractor) and Exhibition Fit-Out (which was commissioned by the Exhibition Fit-Out Contractor).

The installation of Exhibition Fit-Out began without having finished the construction phase of the building, which led to continuous adjustments in the initial planning. Usually the fit-out work doesn't start until the construction is finished and clean and the building is dust free.

Within the Exhibition Fit-Out area there were three main operational processes: Furniture, Showcases and Content (objects and information). The first two prepared the continent on which the objects would be installed. Their problems and delays mediated the operability of the installation of objects. 
An important particularity is that the three main operational processes work in parallel, the first two ones (furniture and showcases) are necessary to operate the third one (objects). The processes of each one are the following:

\begin{tabular}{|c|c|c|c|c|c|c|c|}
\hline Showcases & Design & $\begin{array}{c}\text { Prototype and } \\
\text { acceptance }\end{array}$ & Production & Logistics & Adjustments & Adjustments & Approval \\
\hline Furniture & Design & $\begin{array}{c}\text { Prototype and } \\
\text { acceptance }\end{array}$ & Production & Logistics & Installation & Adjustments & Approval \\
\hline Objects & $\begin{array}{c}\text { Design of } \\
\text { layout } \\
\text { elements }\end{array}$ & $\begin{array}{c}\text { Design of } \\
\text { support } \\
\text { elements and } \\
\text { graphics }\end{array}$ & $\begin{array}{c}\text { Preparation } \\
\text { of support } \\
\text { elements }\end{array}$ & $\begin{array}{c}\text { Preparation } \\
\text { of graphics }\end{array}$ & $\begin{array}{c}\text { Iinstallation } \\
\text { of objects } \\
\text { and graphics }\end{array}$ & $\begin{array}{c}\text { Lighting } \\
\text { settings }\end{array}$ & $\begin{array}{c}\text { Review and } \\
\text { approval }\end{array}$ \\
\hline
\end{tabular}

Table 1. The three main operational processes

The installation process of objects had to be delayed due to the lack of client-approved showcases. At the time when the beginning, improvement project after detecting the problem, was established, there were 150 showcases installed of the total of 247 . The client had only approved 20, mainly due to their demand for aesthetic finishes much higher than the usual quality standards. In addition, no display case had the client-approved security installation.

To give an idea of the volume that the process of installation of showcases represents, it can be used as reference that the Spanish National Museums, from which information has been collected, have about $20 \%$ of the showcases alarmed and in many cases wirelessly. The object of this work has 247 showcases connected by wire and a number of almost 3000 security elements installed. In comparative terms, the number of showcases in the National Archaeological Museum in Madrid is 337 (Museo Arqueológico Nacional, 2014).

As a tool for analysis and improvement of processes, in this research the CMP methodology by Berenguer and Ramos-Yzquierdo (2008) is used. Also, in this procedure a lean guidance and the process innovation techniques are used, such as identification Process mapping, value mapping, relevance matrix and robustness, process form creation, value-added analysis (VAA) and process modeling techniques.

The project above-mentioned presents a large number of processes that have not been regulated or written previously. Given the complexity of cultures and organizational structure, many of the activities to be carried out are slowed because their implementation requires developing many steps mostly bureaucratic. Consequently, in order to achieve the main objective of this project, both the improvement of the security process in showcases and the capabilities are analyzed. Furthermore, the challenges to be achieved are set out in the table below using as an indicator the number of errors in inspections of the alarms in showcases. In this sense, to increase client satisfaction by providing a sense of security in the protection of installed objects and solve or alleviate the coordination problems encountered are relevant challenges to managers in museums.

\begin{tabular}{|l|l|}
\hline Capabilities & Challenges \\
\hline Speed & $\begin{array}{l}\text { To reduce some activities that do not add value, such as excessive inspections by the client } \\
\text { NMO) }\end{array}$ \\
\hline To be agile & $\begin{array}{l}\text { To be able to react to rejections, analyze, repair and turn in inspection again the alarms in } \\
\text { showcases. Learn to do the first }\end{array}$ \\
\hline Alignment to the Client & To gain confidence by the client in a process that is improved day by day \\
\hline Innovation & $\begin{array}{l}\text { To improve the working and operational methods looking for alarm assemblies in showcases, } \\
\text { and get done first time. }\end{array}$ \\
\hline
\end{tabular}

Table 2. Capabilities and challenges 
The client (NMO) did not coordinate the execution of the study process: there was no Security Manager (who should be in charge of the control of the security system in showcases as well as in the whole museum) and the Security Consultant merely over-sees the process.

The literature review is presented in the following section. Details of the methodology are presented in section 3 , results are presented in section 4 and the theoretical contribution and managerial implications are discussed in section 5 .

\section{Literature Review}

According to Camarero et al. (2015) and Gómez-Martín (2015), the context in which museums operate has evolved considerably over the last few decades, while the challenges they face have increased. This is because the current need for museums to augment their own revenue and improve their performance coupled with the transformation of cultural models towards more experiential services has led many to adopt a consumer orientation in an effort to make museums and their collections increasingly accessible to visitors.

This visitor orientation is more than just a wish to bring culture closer to the public, but rather a desire to understand visitors' demands and thus adapt to their expectations. Specifically, technological innovation and tradition are two relevant alternative strategies to respond to visitor expectations. According to Ahmad et al. (2013), many researchers had recognized that museums are important path of broader learning and knowledge institution for the society.

For example, in the last decades several museums have developed a strong interest in technology as their path more towards of leisure industries. However, several authors point out that there are contradicting opinions arising between using "traditional" approach and "interactive" technology exhibition techniques for visitor learning (Byrne, 1993; De Backer et al., 2014; De Graaf et al., 2014; Entradas-Silva et al., 2016).

In this sense, De Backer et al. (2014) conclude that many educational practices within an art museum setting lack a substantial theoretical ground to underpin visual arts mediation. According to these authors, this is the reason why the absence of theoretical foundations and well-defined aims is detrimental to the quality of learning processes of museum visitors. Constructivist theories consider a multilayered structure of museum learning to meet visitors' diverse learning needs which presupposes different strategies from the museum staff. Also, Martella, Miraglia, Frost, Cattani and van Steen (2016) conclude that fine-arts museums design exhibitions to educate, inform and entertain visitors, existing work leverages technology to engage, guide and interact with the visitors, neglecting the need of museum staff to understand the response of the visitors.

Kabassi (2016) and Kiourt et al. (2016) consider that the modern technologies and the web have changed the way the users interact with museum exhibits providing alternative interactions and many advantages. In this sense, several studies have focused on the methods used and tried to categorize the experiments found in the literature with respect to the method used. This researcher describes the tools that may be used for implementing an evaluation experiment, and emphasis is given on the evaluation of special aspects of the use of Information and Communication Technologies (ICTs) in museums such as the use of handheld devices as well as Virtual Reality tours.

Furthermore, Pérez-Sanagustín, Parra, Verdugo, García-Galleguillos and Nussbaum (2016) describe those new device solutions as Quick Response (QR) code technologies offer potentially outstanding opportunities to transform public experience in museum-like spaces. However, although QR codes are a cost-effective way of delivering digital information in these spaces, there is as yet little information on the resulting effects on visitor engagement. In their research, these authors conducted two different controlled experiments in order to examine the effects of QR codes on visitor engagement in museum-like spaces; experiments structured in two research cycles and followed the Design-Based Research methodology. The first experiment compared the effects of QR codes versus traditional display screens for providing information about the exhibits, and the second experiment compared traditional (or one-way) QR codes with two-way QR codes as different methods for delivering information. Two-way QR codes allow visitors to search for information about the exhibit, as well as contributing by leaving comments. In both experiments the results showed that visitors preferred direct mechanisms for 
obtaining information about the exhibits, such as text on a panel or videos on a screen, but also, they found that two-way QR codes are a cheaper alternative for delivering digital content in museum-like spaces, especially for college-age visitors.

Nowadays, one of the largest challenges of museums is to achieve sustainability by reducing costs and energy demands without jeopardizing conservation and thermal comfort (Entradas-Silva et al., 2016). The evolution of science seems to show a new trend with the application of less stringent targets, but after more than one century of research in the museum environment field there is still not a consensus. The test of the published riskassessment and optimization tools in real cases assumes therefore a fundamental role for the change of the approach.

Proietti, Panella, Leccese and Svezia (2015) point out that monitoring is an essential task in indoor environments, which require particular attention especially if they are affected by a considerable flow of people, as in museum environments. In this line of research, several authors consider that the requirements for visual performance and control of object damage are defined according to the categories of responsivity to light (De Graaf et al., 2014).

In particular, regarding the process of installation and revision of the security system in showcases, recently Sciurpi, Carletti, Cellai and Pierangioli (2015) and ICMS (s.f.) pointed out the results of the environmental monitoring of some rooms of the "La Specola" Museum in Florence, affected by significant overheating problem in summer mainly due to the absence of efficient solar shadings. This analysis showed that temperature and environ-mental conditions were not reasonably acceptable for the preservation of the kind of objects exhibited and specifically, the results can be extended to several historical buildings, where large windows and skylights imply high energy consumption and poor indoor environmental conditions that can cause damage to the artefacts.

In this line of research regarding to the improvement of processes in cultural organizations (Martínez-Martínez \& Cegarra-Navarro 2014; Palmes, 2010; Rosemann \& Broke, 2010; Salgueiro, 1999), recently Napp, Kalamees, Tark and Arumägi (2016) describe that the ruins of medieval Episcopal Castle of Haapsalu in Estonia planned to be taken into use as a museum. According to these authors, due to conservational, architectural or economic reasons, it is difficult or sometimes also impossible to install climate and security systems into historic buildings. Before the design process, indoor climate and security measurements have been carried out to get an overview of the current situation, the needs for changes, to get data for model calibration and to work out the design strategy. In their research, combined heat, air, and moisture simulations were performed with IDA-ICE software together with different indoor climate and security control strategies and different outdoor climatic conditions (typical year, warm summer, cold winter, and humid autumn). In this paper, simulations showed reasonable agreement with field measurements and furthermore, by simulations different climate and security control systems were analyzed and their necessity and the extent of performance were determined.

This paper contributes to literature on the sonic and mobile makings of landscape, in particular for an action research approach concerned with the social, cultural and political dimensions of embodied engagements with landscape practice. According to Rich (2016), this kind of research contributes to recent museum studies literature with its foregrounding of the body and the sensorium in the configuration of the spaces of knowledge at the museum.

\subsection{Linking Knowledge Management and Business Process}

The concept of knowledge management (KM) has been used in different disciplines, mostly in knowledge engineering (Mertins, Heisig \& Vorbeck, 2013). Several researches often reduced the concept of knowledge management to the description of the development and use of expert systems. The current KM practice shows that IT based approaches towards knowledge management are still dominant. IT based KM approaches focus mainly on the storage and distribution of explicit knowledge, thus overlooking the tacit dimension of knowledge. Recently, we observed a trend towards more process and human-based KM approaches focusing more on networking, collaborative (Adamides \& Karacapilidis, 2006) and the exchange of tacit knowledge 
(Cohen \& Levintahal, 1990; Nonaka \& Takeuchi, 1995; Nonaka, 1994; Nonaka \& Toyama, 2003; CegarraNavarro \& Martínez-Martínez, 2017).

On the other hand, in recent years, many organisations have found enterprise modelling, especially business process modelling, to be an effective tool for managing organisational change (Chung, Cheung, Stader, Jarvis, Moore \& Macintosh, 2003). The application of business processing modelling has brought benefits to many organisations, but the models developed tend to be used for reference during business operations and reengineering activities; they rarely play an active role in supporting the day-to-day execution of the processes (Chung et al., 2003).

The organisations know that the sum of procedures to generate, store, distribute and apply knowledge can to improve business performance (Mertins et al., 2013).

According to Cranfield (1998) the knowledge management is the collection of processes that govern the creation, dissemination, and utilization of knowledge to fulfill organisation objectives. Then to integrate knowledge management into business processes is the dominant recommendation.

Then the integration of business process management (BPM) and KM helps companies to improve temporal, qualitative and cost aspects of the provision of goods and services and to increase their innovative capacities (Schmid and Kern, 2014).

There is increasing interest in making workflow systems more adaptive and using knowledge-based techniques to provide more flexible process management support than is possible using current workflow systems (Chung et al., 2003). This paper intends to provide an action research approach that can serve as a framework.

\section{Methods}

As a tool for analysis and improvement of processes, the CMP by Berenguer and Ramos-Yzquierdo (2008) founded in Hammer and Champy (1993) is used for its versatility and flexibility, as well as the process innovation techniques worked with in the cited tool. The process is divided into sequential activities that end in a quality control before the step to the next activity.

It is an eight-phase process, based on Six Sigma DMAIC (Define, Measure, Analyze, Improve and Control). This includes a cycle that can be called "classic", in 5 phases, as DMAIC, considering also two initial phases of introduction to the improvement, and a final (awareness-identification-planning-analysis-design-implementationcontrol-training). Each phase has defined several activities and tools of its own. Given ad-vantages and disadvantages of different methods of continuous improvement, we choose CMP as is at the right level of rigor and flexibility in its travel.

Since it is a project (alarmed of showcases), with a beginning and an end, in which the different phases pass sequentially (with certain overlaps), we look for the opportunity to make the improvement, working with an ongoing process (if possible just at the beginning), so that the improvement over time can be evaluated.

In order to evaluate the improvement, a battery of KPIs is used:

1) Approval of showcases by the client (1.1. \% Showcases approved= Showcases approved / Total showcases and other; 1.2. Number of approved showcases per month= Number of approved showcases / Number of moths since the beginning of the project.

2) Approval of the security installation (\% Approval of the security installation. = Security installation of showcases approved / Total showcases).

3) Showcases with security error when inspected (\% of showcases with error when inspected $=$ Showcases with error when first inspected / total of Showcases inspected).

4) Showcases without connection box (\% Showcases installed without connection box $=$ Number of showcases installed without connection box / Total showcases installed). 
The process was divided into sequential activities (with the figure of supplier and clients in each of them), which ended with a quality control before proceeding to the next one. This reduced the risk of error in the final inspection and thus the reliability of the process.

The AS-IS process mapping is elaborated and the main KFSs and KPIs are established in order to improve the degree of dissatisfaction and the inefficiencies in coordination. Also, in this project is being establishing the percentage of approval of showcases by the client (measured in percentages on the total of the project, and in number of approved showcases per month), number of repairs to be made in each case and furniture submitted for inspection.

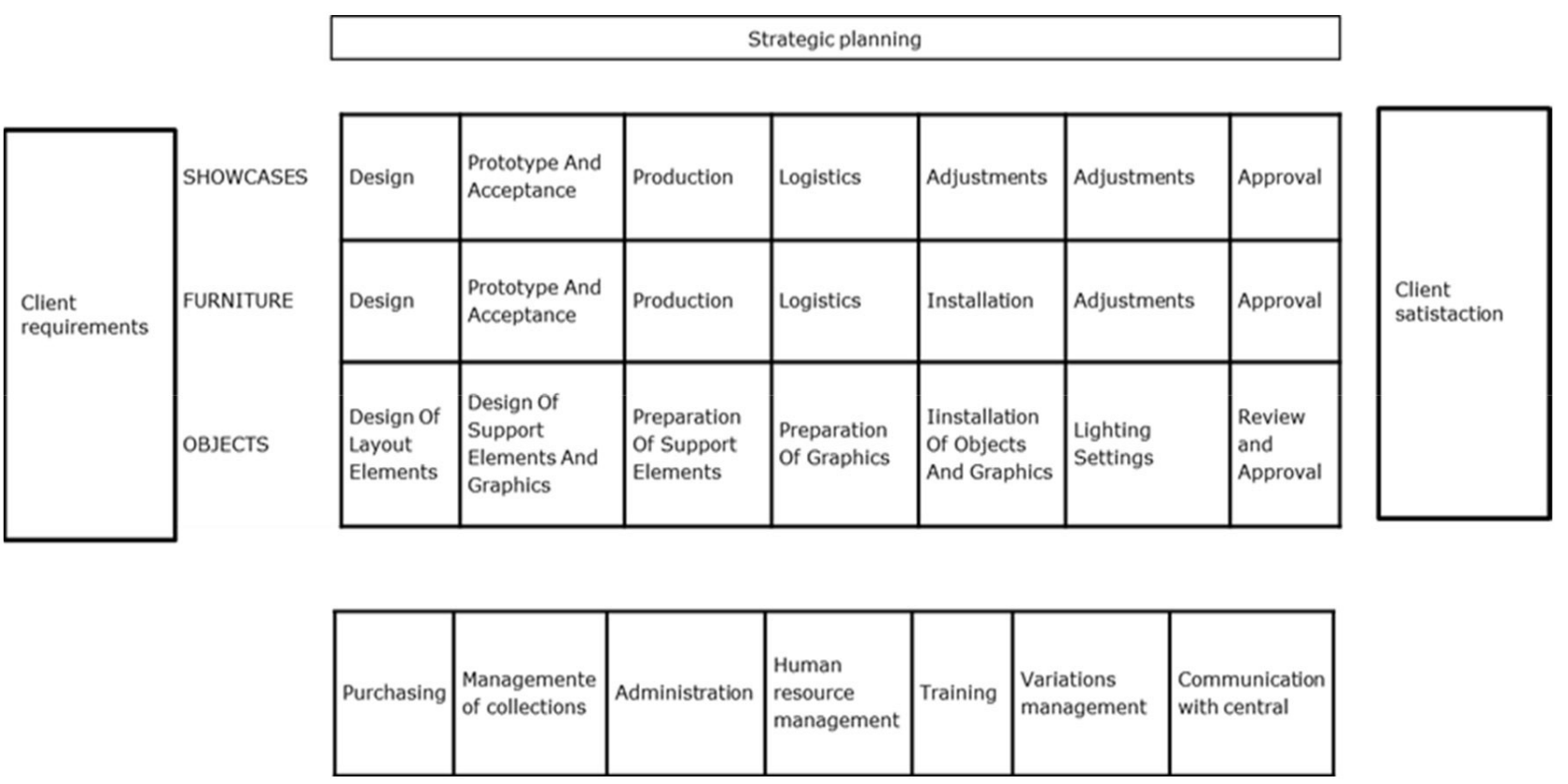

Figure 2. AS-IS Process Mapping

Also, in this project it is established a list of selection criteria focused on reducing avoidable dissatisfaction. In order to analyze the situation found in the company which installs the security in the showcases, a study was made of all the important processes in which the company works. This focus on the three operational branches, furniture, showcases and objects has already been mentioned in previous paragraphs. Usually the showcase process includes the installation of security but the diverse problems detected generate the need to manage this subprocess independently.

In the case of a project with a beginning and a point of end, in which the different phases run sequentially, the opportunity is sought for the improvement, that is to say, to work with a process that is underway and, if possible, in the process of being evaluated, so that it can be evaluated this improvement over time. Consequencely, the key decision criteria are determined.

- Degree of client satisfaction with the level of service.

- Degree of avoidable dissatisfaction (number of solvable problems that would cause dissatisfaction).

- Extrapolation to other projects.

- Opportunity to make the improvement.

- Reduction of operational waste.

Table 3. Key decision criteria 
Among all the operational processes detected in this project, by means of using the technique of two-dimensional process analysis, it is assessed the main priority for an immediate improvement. The relevance (that is, the process generates value) and robustness (that is, the process has the qualities to give the expected service) is valued.

In order to establish the criteria of relevance and robustness, we have considered the problems that affect its operation and identify the relevance and robustness according to high, medium and low grades. Given the timing of the project, in which several phases have already been completed, only those that are in progress are valued. According to the valuations, the processes will be placed in the following quadrants:

\begin{tabular}{|c|l|}
\hline Quadrant & Process Strategy Plan \\
\hline Q1 & Priority processes that require immediate improvement \\
\hline Q2 & Key Competence. Market differentiations to be exploited \\
\hline Q3 & Offer of potential services \\
\hline Q4 & Potential Candidate to Outsourcing \\
\hline
\end{tabular}

Table 4. Quadrants of classification of the identified processes

The responsible of the process improvement in concordance with the department managers involved in the processes decided on the process candidates for improvement. The assessment of the candidates for improvement is presented in the following table:

\begin{tabular}{|c|c|c|c|}
\hline Processes & Relevance & Sturdiness & Quadrant \\
\hline Installation of showcases & High & Medium & Q2 \\
\hline Adjustments in showcases & High & Medium & Q2 \\
\hline Preparation of graphics & Medium & Medium & Q3 \\
\hline Supervision of showcases & High & Low & Q1 \\
\hline Review of security in installation of showcases & High & Low & Q1 \\
\hline Logistics of showcases & Low & High & Q4 \\
\hline Adjustments of illumination & Low & High & Q4 \\
\hline Review and approval in installation of objects & High & Medium & Q2 \\
\hline
\end{tabular}

Table 5. Assessment of the candidate for improvement

Determining that the most relevant actions for improvement are the following: Inspection of showcases and revision of the security installation in showcases, between the two processes the second one is selected. This fact complies with all the key decision criteria above-mentioned, in particular because it is a very appropriate moment to carry out the improvement. For this reason, it requires an effort in coordination, and it can be extrapolated to other projects, it must involve a reduction in the waste of the operations and also it must reduce the degree of avoidable dissatisfaction.

\section{Results}

The museum has 247 showcases. At the time of the start of this study more than 100 were installed and there were 25 in the installation phase, but none had the security tested. At the start of the study, no security facility had been successfully inspected, despite having approved 28 of the 53 already completed.

At the end of the project, security had been inspected for all showcases, even some of them yet not approved by the client. 


\begin{tabular}{|c|c|c|c|c|c|c|c|c|c|c|c|c|c|c|}
\hline \multirow[b]{2}{*}{ Gallery } & \multirow[b]{2}{*}{$\begin{array}{c}\text { Total } \\
\text { showcases }\end{array}$} & \multirow[b]{2}{*}{$\begin{array}{c}\text { Total } \\
\text { objects }\end{array}$} & \multirow{2}{*}{$\begin{array}{c}\text { Number } \\
\text { of } \\
\text { objects/ } \\
\text { showcase }\end{array}$} & \multicolumn{2}{|c|}{$\begin{array}{c}\text { Phase 1: } \\
\text { Installation of } \\
\text { showcases }\end{array}$} & \multicolumn{3}{|c|}{$\begin{array}{c}\text { Phase 2: } \\
\text { Junction boxes }\end{array}$} & \multicolumn{2}{|c|}{$\begin{array}{l}\text { Phase } 3: \\
\text { Security }\end{array}$} & \multicolumn{4}{|c|}{$\begin{array}{l}\text { Phase 4: } \\
\text { Security }\end{array}$} \\
\hline & & & & Installed & $\begin{array}{c}\% \\
\text { installed }\end{array}$ & $\left|\begin{array}{c}\% \text { ready } \\
\text { to } \\
\text { install }\end{array}\right|$ & $\begin{array}{l}\text { Showca } \\
\text { ses and } \\
\text { boxes }\end{array}$ & total $\%$ & $\left|\begin{array}{c}\text { Reviewed } \\
\text { per OHI- } \\
\text { APD }\end{array}\right|$ & $\%$ & $\begin{array}{l}\text { Reviewed } \\
\text { per OHI- } \\
\text { APD-ACE }\end{array} \mid$ & $\%$ & Objects & $\%$ \\
\hline LP & 34 & 625 & 18 & 0 & $0 \%$ & 2 & 32 & $100 \%$ & 0 & $0 \%$ & 0 & $0 \%$ & 0 & $0 \%$ \\
\hline MH & 8 & 53 & 7 & 6 & $75 \%$ & 2 & 6 & $100 \%$ & 6 & $75 \%$ & 1 & $13 \%$ & 4 & $8 \%$ \\
\hline AA & 15 & 214 & 14 & 11 & $73 \%$ & 2 & 13 & $100 \%$ & 9 & $60 \%$ & 11 & $73 \%$ & 175 & $82 \%$ \\
\hline $\mathbf{C M}$ & 20 & 78 & 4 & 0 & $0 \%$ & 0 & 0 & $0 \%$ & 0 & $0 \%$ & 0 & $0 \%$ & 0 & $0 \%$ \\
\hline AF & 2 & 20 & 10 & 0 & $0 \%$ & 0 & 1 & $50 \%$ & 0 & $0 \%$ & 0 & $0 \%$ & 0 & $0 \%$ \\
\hline $\mathrm{CU}$ & 3 & 388 & 129 & 0 & $0 \%$ & 3 & 0 & $100 \%$ & 0 & $0 \%$ & 0 & $0 \%$ & 0 & $0 \%$ \\
\hline TL & 7 & 40 & 6 & 7 & $100 \%$ & 0 & 7 & $100 \%$ & 7 & $100 \%$ & 7 & $100 \%$ & 40 & $100 \%$ \\
\hline PH bat & 3 & 61 & 20 & 1 & $33 \%$ & 0 & 3 & $100 \%$ & 0 & $0 \%$ & 0 & $0 \%$ & 0 & $0 \%$ \\
\hline PH fri & 12 & 50 & 4 & 10 & $83 \%$ & 0 & 12 & $100 \%$ & 10 & $83 \%$ & 11 & $92 \%$ & 49 & $98 \%$ \\
\hline PH magan & 28 & 899 & 32 & 20 & $71 \%$ & 3 & 22 & $89 \%$ & 22 & $79 \%$ & 22 & $79 \%$ & 657 & $73 \%$ \\
\hline SI & 41 & 262 & 6 & 34 & $83 \%$ & 0 & 41 & $100 \%$ & 39 & $95 \%$ & 12 & $29 \%$ & 59 & $23 \%$ \\
\hline OW & 25 & 571 & 23 & 4 & $16 \%$ & 9 & 16 & $100 \%$ & 0 & $0 \%$ & 0 & $0 \%$ & 0 & $0 \%$ \\
\hline $\mathbf{R N}$ & 9 & 235 & 26 & 4 & $44 \%$ & 1 & 6 & $78 \%$ & 0 & $0 \%$ & 1 & $11 \%$ & 6 & $3 \%$ \\
\hline IH & 5 & 41 & 8 & 5 & $100 \%$ & 0 & 5 & $100 \%$ & 5 & $100 \%$ & 5 & $100 \%$ & 41 & $100 \%$ \\
\hline $\mathrm{CO}$ & 8 & 333 & 42 & 0 & $0 \%$ & 7 & 1 & $100 \%$ & 0 & $0 \%$ & 0 & $0 \%$ & 0 & $0 \%$ \\
\hline UC & 12 & 50 & 4 & 0 & $0 \%$ & 0 & 12 & $100 \%$ & 0 & $0 \%$ & 0 & $0 \%$ & 0 & $0 \%$ \\
\hline Others & 4 & 3 & 1 & 0 & $0 \%$ & 3 & 0 & $75 \%$ & 0 & $0 \%$ & 0 & $0 \%$ & 0 & $0 \%$ \\
\hline \multirow[t]{2}{*}{ Temporary } & 11 & 0 & 0 & 0 & $0 \%$ & 3 & 0 & $27 \%$ & 0 & $0 \%$ & 0 & $0 \%$ & 0 & $0 \%$ \\
\hline & 247 & 3923 & 16 & 102 & $41 \%$ & 35 & 177 & $86 \%$ & 98 & $40 \%$ & 70 & $28 \%$ & 1031 & $26 \%$ \\
\hline
\end{tabular}

Table 6. Display control milestones for cabinets and security elements

\begin{tabular}{|c|c|c|c|}
\hline $\begin{array}{c}\text { Key performance } \\
\text { indicators }\end{array}$ & $\begin{array}{c}\text { Initial of the } \\
\text { process }\end{array}$ & $\begin{array}{c}\text { Forecast for } \\
\text { improvement }\end{array}$ & $\begin{array}{c}\text { Real } \\
\text { results }\end{array}$ \\
\hline Approval of showcases by the client & $48(11.3 \%)$ & $150(60.7 \%)$ & $103(41.7 \%)$ \\
\hline Showcases per month & 4 & 20 & 25 \\
\hline Approval of the security installation & 0 & 150 & 140 \\
\hline$\%$ of showcases with mistakes in the inspection & $72 \%$ (first inspection) & $5 \%$ (second inspection) & $2.3 \%$ \\
\hline Showcases without connection boxes & 45 & 15 & 14 \\
\hline
\end{tabular}

Table 7. Evolution of the approval of the security installation in showcases

The CPM methodology was iterated several times, due to the progress of other processes shortened the deadlines and more speed was needed to successfully finish on time.

The increasing robustness of the process under study allowed its re-elaboration and adjustment to the new needs in each iteration.

It was possible to work in coordination under the command of the company that had greater interest in the process: The Exhibition Fit-Out Contractor. It was done adjusting the works of their subcontractor Installer of Showcases and the installer of Junction boxes (element of union to the general security system of the museum).

The lack of a Security Manager was supplied by delivering each of the display show-cases at the end of the project with the security system completely checked (according to the Security Consultant and the Museum Security 
Installator). At the end of the project this process was continually adapted to the main Process of Installation of Objects to which it served as support process.

\section{Conclusions, Contributions and Implications}

Significant and better contributions related to theoretical foundations and empirical results are relevant in order to inform organizations to the opportunity of being open to the opinions and demands of clients. In this sense, many decisions and actions have to be taken into consideration in the management process of institutions and specifically in museums, however this paper is only oriented to enhance our insight into their management process when managers are implementing different activities in their operational activities.

In spite of the different opinions of clients and visitors in museums, definitely there is a wide variety of contributions reporting that management processes can be implemented and improved a timely manner through validated knowledge. Interventions focused to add value for the visitors have caused significant gains in test scores, but indicators such as reduction of operational waste and opportunity to make the improvement also have improved financial and economic performance; furthermore, these management and operational processes in museums -evidenced by degree of clients' satisfaction and avoidable dissatisfaction- have increased satisfaction of visitors at institutions. For these reasons, the elimination of errors in terms of obstacles to economic performance in museums is of special relevance in the context of operational activities to increase the number of clients and visitors visiting the museums.

In short, the main relevant implication for academics and practitioners of this paper is in order to present a methodology to improve the museum processes focusing on the reduction of errors and also adding value for the visitors. In this sense, this research has analyzed the degree of avoidable dissatisfaction (that is, the number of solvable problems that would lead to dissatisfaction), the opportunity for improvement, the reduction of operational waste and the need for coordination in a relevant museum in the world. Regarding to the main objective presented at the beginning of this paper, the above-mentioned four characteristics exposed are identified as key decision factors to characterize the satisfaction of the clients and clients. Also, this paper reinforces that certain key performance indicators are very important in the management process in institutions as museums. The main contributions for academics, practical implications, limitations and further research that emerge from this research are showed below.

In the case of the National Museum of Oman, the process of installation and revision of the security system in showcases was especially delicate and complex. The work of coordination between companies without direct contractual ties, through the vision and awareness as a process, improved the process under study. Its improvement pushed the improvement of other processes helping to contribute to the added value perceived directly by the client.

As the results obtained by the process improvement initiative show, we highlight the improvement in all aspects regarding the security in showcases. The performance indicators of the improvement process (approval of the security installation, percentage of showcases with security error when inspected and showcases installed without connection box) have improved significantly, and even more in relation to the general performance indicator of showcases (approval of showcases by the client).

The current work has served as a repository of knowledge applicable to new similar projects, in which to take into account the peculiarities of each case and in particular the level of quality demanded by the client. That is, this repository represents all the experiences captured by contractors and organizations here involved during the previous processes as lessons learned and best practices. It is important to take into account the degree of avoidable dissatisfaction (number of solvable problems that would lead to dissatisfaction), the opportunity for improvement, the reduction of operational waste and the need for coordination.

To reinforce the relevance of certain management indicators is verified in the museum reinforcing the importance to intervene on certain relevant variables at different levels of management performance. 
Among the limitations in the work there was: the complexity of implementing indicators and the partial vision of the project as data were only obtained from a part of one of the companies involved in the construction of the museum.

Improving the quality of leisure services has become a crucial issue, in particular in order to the identification of certain challenges regarding the nature and competitiveness of cultural services. The challenge is to further improve the process and the knowledge generated, to undertake the improvement of other processes and to serve as a reference for extrapolating to future projects.

\section{Declaration of Conflicting Interests}

The authors declared no potential conflicts of interest with respect to the research, authorship, and/or publication of this article.

\section{Funding}

The authors received no financial support for the research, authorship, and/or publication of this article.

\section{References}

Adamides, E.D., \& Karacapilidis, N. (2006). A knowledge centred framework for collaborative business process modelling. Business Process Management Journal, 12(5), 557-575. https://doi.org/10.1108/14637150610690993

Ahmad, S., Abbas, M.Y., Yusof, W.Z., \& Taib, M.Z.M. (2013). Museum Learning: Using Re-search as Best Practice in Creating Future Museum Exhibition. Procedia - Social and Behavioral Sciences, 105(3), 370-382.

https://doi.org/10.1016/j.sbspro.2013.11.039

Berenguer, J.M., \& Ramos-Yzquierdo, J.A. (2008). Manual de técnicas de CMP: herramientas para la innovación de procesos. Bilbao: EUNSA.

Byrne, J.A. (1993). The horizontal corporation. Business Week, 20, 76-81.

Camarero, C., Garrido, M.J., \& Vicente, E. (2015). Achieving effective visitor orientation in Eu-ropean museums. Innovation versus custodia. Journal of Cultural Heritage, 16(2), 228-235. https://doi.org/10.1016/j.culher.2014.05.006

Cegarra-Navarro, J.G., \& Martínez-Martínez, A. (2017). Gestión de conocimiento. Una ventaja competitiva. Madrid: ESIC.

Chung, P.W.H., Cheung, L., Stader, J., Jarvis, P., Moore, J., \& Macintosh, A. (2003). Knowledge-based process management: An approach to handling adaptive workflow. Knowledge-Based Systems, 16(3), 149-160. https://doi.org/10.1016/S0950-7051(02)00080-1

Cohen, W.M., \& Levintahal, D. (1990). Absorptive capacity: A new perspective on learning and innovation. Administrative Science Quarterly, 35, 128-152. https://doi.org/10.2307/2393553

Cranfield, B.S. (1998). Europe's state of the art in knowledge management. London: Information Strategy, The Economist Group.

De Backer, F., Peeters, J., Buffel, T., Kindekens, A., Romero-Reina, V., Elias, W. et al. (2014). An Integrative Approach for Visual Arts Mediation in Museums. Procedia - Social and Behavioral Sciences, 143(14), 743-749. https://doi.org/10.1016/j.sbspro.2014.07.419

De Graaf, T., Dessouky, M., \& Müller, H.F.O. (2014). Sustainable lighting of museum buildings. Renewable Energy, 67, 30-34. https://doi.org/10.1016/j.renene.2013.11.035

Entradas-Silva, H., Henriques, F.M.A., Henriques, T.A.S., \& Coelho, G. (2016). A sequential process to assess and optimize the indoor climate in museums. Building and Environment, 104, (1), 21-34. https://doi.org/10.1016/j.buildenv.2016.04.023

Gómez-Martín, J. (2015). La seguridad en los museos. Introducción, conceptos fundamentales y legislación. Madrid: Bubok. 
Hammer, M., \& Champy, J. (1993). Reengineering the corporation: A Manifesto for Business Revolution. NY: Harper Business.

ICMS (s.f.). Seguridad en los museos. Comité para la seguridad en los museos. Available at: http://icom.museum/los-comites

Kabassi, K. (2016). Evaluating websites of museums: State of the art. Journal of Cultural Heritage, Available online 14 November (in press).

KEA European Affairs (2009). The impact of culture on creativity, A Study Prepared for the European Commission (Directorate-General for Education and Culture), June.

Kiourt, C., Koutsoudis, A. \& Pavlidis, G. (2016). DynaMus: A fully dynamic 3D virtual museum framework. Journal of Cultural Heritage, 22, 984-991. https://doi.org/10.1016/j.culher.2016.06.007

Martella, C., Miraglia, A., Frost, J., Cattani, M., \& van Steen, M. (2016). Visualizing, clustering, and predicting the behavior of museum visitors. Pervasive and Mobile Computing, Available online 31 August (in press).

Martínez-Martínez, A., \& Cegarra-Navarro, J.G. (2014). Gestión por procesos de negocio. Organización horizontal. Madrid: Ecobook, Editorial del Economista.

Mertins, K., Heisig, P., \& Vorbeck, J. (2013). Knowledge management: concepts and best practices. NY: Springer Science \& Business Media.

Museo Arqueológico Nacional (2014). Museo Arqueológico Nacional. Un museo totalmente renovado. Nota de Prensa, 1-33. Madrid. Available at: http://www.man.es/man/museo/prensa.html

Napp, M., Kalamees, T., Tark, T., \& Arumägi, E. (2016). Integrated Design of Museum's Indoor Climate in Medieval Episcopal Castle of Haapsalu. Energy Procedia, 96, 592-600. https://doi.org/10.1016/j.egypro.2016.09.105

Nonaka, I. (1994). A Dynamic Theory of Organizational Knowledge Creation. Organization Science, 5(1), $14-37$. https://doi.org/10.1287/orsc.5.1.14

Nonaka, I., \& Takeuchi, H. (1995). The knowledge-creating company: How Japanese companies create the dynamics of innovation. Oxford: Oxford University Press.

Nonaka, I., \& Toyama, R. (2003). The knowledge-creating theory revisited: knowledge creation as a synthesizing process. Knowledge Management Research \& Practice, (1), 2-10. https://doi.org/10.1057/palgrave.kmrp.8500001

Palmes, C. (2010). PDCA: Planificar, hacer, verificar, actuar. Madrid: AENOR.

Pallud, J., \& Straub, D.W. (2014): Effective website design for experience-influenced environments: The case of high culture museums. Information \& Management, 51, 359-373. https://doi.org/10.1016/j.im.2014.02.010

Pérez-Sanagustín, M., Parra, D., Verdugo, R., García-Galleguillos, G., \& Nussbaum, M. (2016). Using QR codes to increase user engagement in museum-like spaces. Computers in Human Behavior, 60, 73-85.

https://doi.org/10.1016/j.chb.2016.02.012

Proietti, A., Panella, M., Leccese, F., \& Svezia, E. (2015). Dust detection and analysis in museum environment based on pattern recognition. Measurement, 66, 62-72. https://doi.org/10.1016/j.measurement.2015.01.019

Rich, J. (2016). Sound, mobility and landscapes of exhibition: radio-guided tours at the Science Museum, London, 1960-1964. Journal of Historical Geography, 52, 61-73. https://doi.org/10.1016/j.jhg.2016.02.010

Rosemann, M., \& Broke, J. (2010). The six core elements of business process management. Berlin: Springer. https://doi.org/10.1007/978-3-642-00416-2_5

Salgueiro, S. (1999). Cómo mejorar los procesos y la productividad. Madrid: AENOR.

Schmid, W., \& Kern, E.M. (2014). Integration of business process management and knowledge management: state of the art, current research and future prospects. Journal of Business Economics, (84)2, 191-231.

https://doi.org/10.1007/s11573-013-0683-3 
Sciurpi, F., Carletti, C., Cellai, G., \& Pierangioli, L. (2015). Environmental monitoring and microclimatic control strategies in "La Specola" museum of Florence. Energy and Buildings, (95), 190-201.

https://doi.org/10.1016/j.enbuild.2014.10.061

\section{Appendix. Process Form}

\section{Process Form}

General information:

- Name of the process: Process of revision and approval of the security system in showcases.

- Purpose of the process: Check of all elements of security and approval by the client's design and consultant.

- Objectives: all the security elements installed in each cabinet work correctly, and that their signal is collected by the central alarm system of the museum.

Stakeholders:

- Clients: Museum (final client), general process of approval of showcases, desgn and consulting company.

- Suppliers: company controlling the general safety system in the museum, manufacturer and installer of the showcases and installation company of the junction box between alarm system in showcases and museum central system.

- Other groups: company executing the installation project.

Content of the process:

- Initial of the process: installation of all the safety equipment in each showcase by the installation company and the installer of the junction box.

- End of the process: Approval by the design company and consultant. Connecting the showcases with objects installed to the general security system in the museum.

Subprocesses or large activities included:

- Review of all the security elements by the company installing the showcases.

- Referral to review.

- Check and approval of the system by the design company and consultant.

- Subprocesses or large activities excluded:

- Repair of all small defects in the display case (process that is carried out in parallel to the revision of the security system).

Subprocesses or large activities excluded:

- Repair of all small defects in the display case (process that is carried out in parallel to the revision of the security system).

Prepared by: Project engineer

Date:

Reviewed by: Project manager

Date:

Journal of Industrial Engineering and Management, 2018 (www.jiem.org)

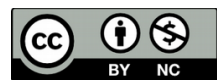

Article's contents are provided on an Attribution-Non Commercial 4.0 Creative commons International License. Readers are allowed to copy, distribute and communicate article's contents, provided the author's and Journal of Industrial Engineering and Management's names are included. It must not be used for commercial purposes. To see the complete license contents, please visit https://creativecommons.org/licenses/by-nc/4.0/. 